\title{
A Most Interesting and Wonderful Time as an Editor
}

\author{
Herbert N. Nigg ${ }^{1}$
}

Received: 21 January 2016/Accepted: 8 February 2016/Published online: 23 February 2016

(C) Springer Science+Business Media New York 2016

I received a telephone call in early January 1983 from Dr. Francis Gunther. His first words were "Can you talk." I had known Francis since August 1974. I had been hired by the University of Florida to investigate the exposure of agricultural labor to pesticides. That included residue analyses to determine pesticide decay and chemical changes in the environment and Dr. Gunther was a world-class expert on that subject. He also had been exceptionally helpful to me as a start-up scientist with huge expectations from my employer. Dr. Tak Iwata, then the editor of the Bulletin, was leaving his postdoc position with Dr. Gunther at UC, Riverside for private industry. Dr. Gunther needed an Editor-in-Chief for the Bulletin. I hesitated about $5 \mathrm{~s}$ and told Dr. Gunther I would be happy to help. I had just taken the first step in a scientific adventure.

I had published some of my first studies in the Bulletin. In those heady early days there were only a few outlets for work on pesticide residues and their importance in the environment. EPA had just been established. DDT had been banned, partly on the work of Dr. James Sternberg at the University of Illinois, Urbana. Dr. Sternberg had discovered the conversion of DDT to DDE after observing robins in convulsions after DDT application to American Elms. My advisor at the University of Illinois was Dr. Robert L. Metcalf whose laboratory was concentrating on the metabolism of pesticides in small fish tank ecosystems. I fully understood the subjects that the Bulletin

\footnotetext{
Herbert N. Nigg

ebennett@uwindsor.ca

University of Florida, Lake Alfred, FL, USA
}

published, but I had no idea the complexities of making that happen.

The first step in my journey was a trip to Heidelberg, Germany, the headquarters for Springer-Verlag. Dr. Gunther introduced me to Conrad Springer, the president of the company. I met editors of all sorts. I was given the circulation numbers for the Bulletin and was introduced to the economics of scientific publishing. Dr. Springer was a charming man, highly intelligent, but unfortunately in the last stages of multiple sclerosis. Dr. Gunther and Dr. Springer are now deceased. I have never forgotten their courtesy and mentoring to a young scientist.

After much discussion with Dr. Gunther and Dr. Springer, I insisted that the Bulletin become a fully peerreviewed journal. This is not to say that the early studies were not first quality. In 1983 the Bulletin was an editorial review journal. Editors are scientists and certainly give good reviews. But I had been told when hired by the University of Florida that it was publish or perish and that meant peer-reviewed journals. So we made Bulletin peerreviewed and changed the text in the frontispiece to reflect the change. In changing to a peer-reviewed journal I created an editorial board. This approximately 120 member board gave us ready reviewers and allowed the board members to list their service on their curriculum vitae and on things like promotion paperwork.

When these changes were in place the editors and I expanded the coverage of scientific subjects. The Bulletin of Environmental Contamination and Toxicology initially covered primarily residue studies and pesticide metabolism studies. Toxicology was the red headed step child. Because I am a trained Toxicologist this seemed like a natural and easy step and it aligned the journal title with the content. In particular we included Aquatic, General and Wildlife Toxicology. We now covered Analytical Methods, Aquatic 
Toxicology - Metals, Aquatic Toxicology - Organics, Environmental Distribution and Human.

Exposure, General Toxicology, Metabolism and Biochemistry, and Wildlife Toxicology. Things ran smoothly. Manuscripts came in at a steady rate, were reviewed and were eventually submitted to the production department as photo-ready.

Our comfort changed in 1991. Dr. Barry Wilson, our Wildlife Toxicology editor, noticed similarities between a study published in the Bulletin in 1989 and one submitted for review in 1991. The authors were eventually banned from publishing in the Bulletin. We became more careful in checking for plagiarism. This effort led to a "Blacklist". That is, we constructed a list of authors and coauthors who could never publish in the Bulletin ever. These details were published (Nigg and Radulescu 1994) and were presented at the Second International Congress on Peer Review in Biomedical Publication, Chicago, IL, September 11, 1993. Shortly after that meeting Springer-Verlag publishing fraud investigations were moved to the New York office.

The Bulletin went electronic about 2000. This was a very large adjustment in our operations. In my opinion it was a huge improvement. We had been a photo-ready journal. Manuscripts were submitted by regular mail and then sent to reviewers. If the manuscript was approved for publication, it had to be formatted. Again, this was done by regular mail. I put together an issue with hardcopies of manuscripts arranged in their order of appearance and mailed it to the production department at Springer. All of the delays and cost of the regular mail were eliminated with electronic submission and processing. Of particular importance, electronic submission opened up worldwide markets with a convenient system.

In 2008 the editors and I made important changes to the requirements for Bulletin publications. We added requirements for measured concentrations of toxicants in controlled toxicology testing. This requirement was driven by Aquatic Toxicology where small ecosystems as test platforms can influence the actual toxicant concentration reaching the test organism. We instituted the requirement for QA/QC statements. This change was prompted because of the use of data published in the Bulletin for regulatory purposes. In the regulatory environment $\mathrm{QA} / \mathrm{QC}$ is required for data to be valid. Similarly proper controls were required. This might require both positive and negative controls depending on the study. We required that proper statistics be conducted. In the statistical world things had evolved, but we had also noticed that some authors tended to use statistical tests that were not conservative and in the worst cases, did not apply to the data set in questions.

Quite early we changed the color of the Bulletin from blue to orange to match the color of the Archives of Environmental Contamination and Toxicology, our companion journal publishing longer and more inclusive studies. Today, the size and format of the Bulletin of Environmental Contamination and Toxicology is matched with the Archives of Environmental Contamination and Toxicology. I believe that the Bulletin has been improved and most certainly poised for the future with convenient and easy manuscript handling and with a new editor-inchief and a new and expanded editorial board.

Over the years I worked with 500 plus scientists, 70 plus of these were Associate Editors with the others as members of the Editorial Board. I wish there were space to express individually my deep gratitude to these fine individuals. As an Editor-in-Chief I was always gratified by the improvements suggested by the Editors and members of the Editorial Board for improving the quality of manuscripts and the scientific influence of the Bulletin. I thank all of the individual scientists who worked with me. You were a joy and made my life interesting and rewarding.

I extend my best wishes to the new Editor-in-Chief and to the scientists working as Editors, Editorial Board members and Reviewers. I believe the Bulletin of Environmental Contamination and Toxicology has a bright future because of these talented people.

\section{Reference}

Nigg HN, Radulescu G (1994) Scientific misconduct in environmental science and toxicology. JAMA 272:168-170 